\section{ENTRE EL MITO Y LA CRÍTICA: LA MEMORIA DEL 68 FRANCÉS}

\author{
Juan María Sánchez-Prieto \\ Universidad Pública de Navarra \\ ORCID iD: https://orcid.org/0000-0003-3380-8068 \\ juanma.sanchez@unavarra.es
}

Cómo citar este artículo/Citation: Sánchez-Prieto, J. M. (2018). Entre el mito y la crítica: la memoria del 68 francés. Arbor, 194 (787): a432. https://doi.org/10.3989/arbor.2018.787n1005

Recibido: 31 enero 2017. Aceptado: 13 noviembre 2017.

RESUMEN: El 68, más que entre la memoria y la historia, se debate entre el mito y la crítica. El mayo francés ha sido una fuente constante de discusión y proliferación de ideas, por lo que no resulta convincente la tesis reciente acerca de una historia oficial o consenso en torno a su significación, fabricado al filo de las conmemoraciones. Partiendo de la doble explosión de la palabra y la acción que supuso el movimiento, en este artículo se pretende profundizar en la cuestión del papel ejercido por los intelectuales en los años 68 , antes y después del epicentro de mayo-junio. Desde esta perspectiva, será más fácil valorar hasta qué punto el debate intelectual sostenido por el ritual conmemorativo ha acabado construyendo una ideología o un pensamiento separado del movimiento y difuminador de sus principales contornos. $\mathrm{O}$ si, por el contrario, es posible concluir en torno al legado actual del 68 , quintaesencia de su memoria.

PALABRAS CLAVE: 68; Francia; pensamiento; discurso; intelectuales; mito; crítica; memoria; legado; conmemoración.

\section{BETWEEN MYTH AND CRITIQUE: THE MEMORY OF MAY '68}

Copyright: (C) 2018 CSIC. Este es un artículo de acceso abierto distribuido bajo los términos de la licencia de uso y distribución Creative Commons Reconocimiento 4.0 Internacional (CC BY 4.0).
ABSTRACT: May 1968, more than a debate between memory and history, is a debate between myth and critique. Le mai français has been a continuous resource of debate and proliferation of ideas, and for this reason the recent position related to the official account or consensus on its significance, fabricated out of the commemorations, lacks plausibility. Starting with the double outburst of word and action (performance) which brought with it the movement, this paper takes into account the role played by the intellectuals in sixty-eight, before and after the May-June epicentre. From this perspective, it will be easier to determine the extent to which the intellectual debate maintained by the commemorative ritual either resulted in a separate ideology or thinking of the movement, which blurred the edges of its main contexts. By contrast, one could also conclude by supporting the present legacy of the 68th, quintessential to its memory.

KEYWORDS: May 1968; France; thinking; narrative; intellectuals; myth; critique; memory; legacy; commemoration. 


\section{INTRODUCCIÓN}

Una de las preocupaciones fundamentales de la historiografía actual es la disquisición entre historia y memoria, sus relaciones y diferencias. La inflación actual de la memoria, de las memorias, hace peligrar la historia, o cuanto menos ha puesto la historia al servicio de la memoria, como antaño lo estuvo al servicio del príncipe o la nación. La contraposición entre la subjetividad de la memoria y la objetividad de la historia se ha vuelto más problemática, pese a los progresos de la historia profesional en el siglo pasado. La ola memorial y conmemorativa lo invade todo, marca la propia agenda del historiador, quien se ve constreñido ante la "pretensión de la memoria colectiva a una verdad más verdadera que la veracidad de la historia" (Nora, 2011, p. 416). La historia acaba reducida a la memoria colectiva del grupo de los historiadores, sometidos ellos mismos a la presión de las memorias sociales fragmentarias. El énfasis en la pluralización de las memorias cuestiona la posibilidad misma de una memoria histórica unitaria, y limita el empeño de la historia a la reconstrucción y explicación de ese juego de memorias.

El 68 no escapa a esta complicación. El 40 aniversario del acontecimiento consagró el 68 como lugar de memoria al tiempo que reivindicaba su historización (Gildea, Mark y Warring, 2013, p. 4). En realidad esa pretensión no es nueva, al menos en Francia. Desde 1989, la asociación Mémoires de 68 procedió a un inventario de fuentes para esa "historia a realizar" (Perrot, 1993), proyecto del que parten algunas elaboraciones recientes (Artières y Zancarini-Fournel, 2015; Zancarini-Fournel, 2008). Los historiadores más implicados en esa tarea no son ajenos a la experiencia del 68 y, como ha hecho notar Jacques Revel valorando en términos genéricos sus visiones recientes de mayo, la especificidad profesional no siempre se corresponde con ausencia de ideologización, y hasta se puede observar un endurecimiento en las posiciones (Callu, 2010, prefacio, pp. 18-21). Fuera de trabajos preferentemente descriptivos, algo semejante ocurre con los investigadores más jóvenes, en su denuncia de los enjuagues de la memoria y el olvido de los hechos frente al predominio de las interpretaciones, a lo que habría contribuido -según algunas percepciones (Ross, 2002/2008, pp. 29-30)- el trabajo contraproducente de los sociólogos.

El 68, más que entre la memoria y la historia, se debate entre el mito y la crítica: desde el principio; no es un efecto acumulado de las sucesivas conmemoraciones, aunque estas hayan repercutido en el "mito poderoso" (Gassert y Klimke, 2009, p. 7) o en la "batalla de la interpretación" (Cornils y Waters, 2010, p. 17). No es posible regresar a los hechos prescindiendo de las representaciones o interpretaciones del 68, que habrían devaluado el carácter mismo de esos sucesos, porque la interpretación arranca del propio 68, es parte del acontecimiento en todo su espesor, no únicamente un componente necesario de cualquier memoria (Bénéton y Touchard, 1970; Dosse, 2010). Por ello, resulta poco consistente la tesis de una historia oficial o de un consenso actual en torno a la memoria del 68 francés, enfatizada por Reynolds, cuando se reconoce al tiempo que, no solo no ha habido ninguna conmemoración oficial patrocinada por el estado, sino que mayo ha sido una fuente constante de discusión y proliferación de ideas, y que por la misma dificultad del tema no se ha llegado a un acuerdo real sobre la cuestión de la interpretación (Reynolds, 2011, p. 30, p. 36, p. 44 y p. 51).

En las páginas que siguen, se pretende profundizar en esta última dimensión. Se valoran por una parte algunos aspectos de los sucesos de mayo íntimamente ligados con las ideas, con objeto de determinar desde dentro la relación entre la doble explosión de la palabra y la acción que significó de modo particular el 68 francés. Ello permitirá una aproximación más medida a la cuestión de la correspondencia entre pensamiento y movimiento, o de manera más concreta al papel ejercido por los intelectuales en los años 68, antes o después del epicentro de mayo. Con esta perspectiva, será más fácil calibrar hasta qué punto el debate intelectual mantenido por el ritual de las conmemoraciones ha acabado construyendo una ideología o un pensamiento separado del movimiento y difuminador de sus principales contornos. $\mathrm{O}$ si, por el contrario, cabe concluir en torno al legado actual del 68, quintaesencia de su memoria, por encima de la radical contraposición entre el mito y la crítica, que tiende a obviar el carácter de la hipercrítica como generadora de nuevos viejos mitos.

\section{LA LIBERACIÓN DE LA PALABRA}

El tema de la concordancia entre pensamiento y acción, y la necesidad en cualquier caso de pensar el acontecimiento, más allá de las categorías ideológicas utilizadas por algunos líderes de la revuelta, se plantea desde el primer momento. La elaboración apresurada de Cohn-Bendit, el referente emblemático del 68 francés, cediendo a los imperativos de la inmediata mercantilización del producto (Cohn-Bendit, 1968, p. 7 y pp. 11-12), se afanó -empeñado en darle la vuelta 
a Lenin- en la presentación farragosa del gauchisme como remedio a la enfermedad senil del comunismo, sin detenerse realmente en las causas del malestar de estudiantes y obreros ni en su forma de expresarlo. Mayor alcance y agudeza, aun en la apelación al mito, refleja la mirada reflexiva vertida entonces por Michel de Certeau (1968, p. 27): “En mayo pasado, se tomó la palabra como se tomó la Bastilla en 1789". Heredero el 68 en Francia de las tradiciones revolucionarias liberales y proletarias del pasado, "el lenguaje de las revoluciones no se aprecia como nuevo hasta que han terminado", escribió a su vez el historiador y activista Vidal-Naquet en la introducción del Journal de la Commune étudiante (1969).

Desde esa perspectiva, el 68 se presenta y recobra actualidad como una liberación de la palabra, la reivindicación del "derecho a hablar" de todos, pero en nombre propio, desde la afirmación de la singularidad. Por primera vez, una revolución social se vuelve un fenómeno de lenguaje, que resulta al mismo tiempo un desafío político (Loyer, 2008, p. 285). La efervescencia de mayo constituyó el "festival de la palabra agente", en todas sus variedades ("de líderes y anónima, de estudiantes y obreros, verbalizada y mural, poética y política, pedagógica y mesiánica, la palabra sin palabras y la palabra ruido"), apuntó Nora (1972, p. 163). Esa dimensión de la palabra en acción, lejos de negar el acontecimiento se integra en él, reforzando desde este plano performativo su misma significación. Más allá de la gestualidad de la calle, es a través del trabajo de la palabra y de la escritura libres como mayo entronca con la mitología revolucionaria, manifestando una voluntad histórica de ruptura: para la propia retórica libertaria, reconquistar la palabra y reescribir de nuevo es hacer (Combes, 1984, p. 106). Una ruptura simbolizada en el rechazo de la sociedad de consumo que, como recogió Certeau, está cuestionando no ya los presupuestos del régimen político, sino las bases del sistema entero que la sustenta.

La palabra impertinente y excesiva, como nueva arma simbólica, se convierte en una fuerza de emancipación política y hace del 68 toda una experiencia cotidiana de la política (Canut, 2011, pp. 11-12 y p. 18). La abolición del silencio, la palabra desatada en la calle contra el sistema de relaciones jerárquicas, la invasión del poder y los valores tradicionales responde antes que nada a la propia necesidad de liberar el malestar acumulado. "Teníamos una idea bíblica de la palabra" (Daum, 1988, p. 111). No fue el pasatiempo de los pasivos, ni la libertad formal concedida a los impotentes (Cusset, 2008, p. 130), contestan los mi- litantes a sus críticos. Uno de los primeros fue Aron, para quien ese "maratón de palabras" era simple palabrería emocional (Aron, 1968, pp. 31-32). El mito de la barricada cobra así un nuevo sentido: pierde su utilidad militar para entenderse como la "delimitación de un lugar de la palabra, de un lugar donde el deseo puede inscribirse y llegar a la palabra", suprimiendo las barreras internas (Geismar, July y Morane, 1969). Un grafiti parisino lo expresaba claramente: "La barricada cierra la calle pero abre la boca" (Rohan, 1988, p. 114). Se convierte en la expresión de un aire de libertad, de un ansia de vivir y de cambiar el mundo, de un compromiso contra el conformismo creado por el propio consumismo que comenzase por vivificar el lenguaje (y la universidad), devolviendo a la palabra toda su verdad y poder.

Como es sabido, el lenguaje vital del 68, antes que en boletines, papeles y manifiestos, se plasmó en los muros de París. Para que las palabras no se las llevara el viento. La ciudad como libro colectivo (Combes, 1984, p. 114 y pp. 121-122), aparentemente elaborado sin orden ni concierto, ni finalidad alguna, contiene la "palabra salvaje" (Barthes, 1968, pp. 109-110) de las auténticas fuerzas vivas anónimas del movimiento, multiplicando el rol de escritor público, en su intento de producir discurso contra el orden establecido o simplemente de desenmascarar a través del humor, la parodia, la paradoja o lo insólito los límites de todos los viejos discursos (Vivero, 2011) ${ }^{1}$. La crítica de Ross (2002/2008, pp. 355-361) descalifica el lenguaje de los muros para primar el de los panfletos y publicaciones de los grupos y organizaciones instalados en una reconocible retórica marxista. Este es sin duda más ideológico, pero no más representativo del fenómeno, y evidentemente menos novedoso. Su análisis combate una imagen forzada del 68 como rebelión de una juventud poetizada y niega a los estudiantes una verdadera dimensión de sujeto político para reivindicar el movimiento de masas y el protagonismo obrero (Ross, 2002/2008, pp. 388-391), como ya hicieran los principales grupos gauchistes después de los sucesos (Sánchez-Prieto, 2001, pp. 121-123).

Los estudiantes abrieron y ofrecieron la palabra a los intelectuales y obreros, pero lo cierto es que el gauchisme tuvo dificultad para articular esa palabra liberada. Si los jóvenes manifiestan el deseo de romper definitivamente con lo ya dicho, los obreros tuvieron mucha más dificultad para prescindir del lenguaje instalado en su propio medio (Canut, 2011, pp. 19-20). El movimiento del 22 de marzo buscó el engarce de estudiantes-obreros a través de los comités de acción, 
nuevas formas de organización al margen de los grupos políticos existentes, con el fin de que la "voz de los trabajadores domine por fin la mentira de la burguesía" (citado por Duteuil, 2008, p. 141)². Sin embargo, su presencia dentro de las empresas y lugares de trabajo será muy escasa, lo que no afecta a la magnitud y éxito de la huelga obrera. Al margen del grupo surgido en Nanterre, fueron los situacionistas quienes más próximos se mostraron del lenguaje nuevo de mayo, inspirando una parte significativa de aquellos grafitis. Inscripciones como "Queremos vivir", "Vivir sin tiempos muertos", "Toma la vida", "El aislamiento alimenta la tristeza", "Sed solidarios y no solitarios", "La cultura es la inversión de la vida", "Creatividad, espontaneidad, vida" ${ }^{3}$, resumen bien esa presencia y el propio objeto de la liberación de la palabra: poner el lenguaje al servicio de la vida ${ }^{4}$.

La crítica situacionista del arte y la cultura separados de la vida repercute en una crítica de la política, que es al mismo tiempo una llamada a la política creativa -no reducible a la poesía revolucionaria- con objeto de favorecer una "intervención creativa directa en la realidad" que disponga la vida cotidiana en el centro de la cuestión social (Ghirardi, 2003, pp. 15, 23-25). Esta voluntad de vivir y de forjar una nueva civilización que trascienda la cosificación económica, está en la base de la politización masiva de los jóvenes alrededor del 68. Ello conllevará después de los sucesos -superada la hostilidad y la parálisis iniciales de los viejos partidos frente al movimiento- una transformación de las propias organizaciones políticas de juventud, tanto en las formaciones de derecha como de izquierda, fomentando la participación y el compromiso, lo que contribuirá a una renovación de la democracia interna, aunque el recorrido resultase efímero (Dubois, 2014, p. 19, p. 127 y pp. 403-407). Tampoco la Internacional Situacionista sobrevivió al post-68, aunque el núcleo de sus ideas, así como la invocación a una nueva política sensible a la vida de la gente, tenga en la actualidad vigencia, por encima de los grupos o líderes políticos que aparentan capitalizarlas, y de la conexión real que quepa establecer con los trabajadores.

\section{EL PAPEL DE LOS INTELECTUALES}

El papel jugado por los intelectuales antes y después de mayo sigue provocando controversia. La primera cuestión que se plantea son los referentes teóricos de los estudiantes y los posibles inspiradores ideológicos del movimiento, o al menos de los principales grupos gauchistes (troskistas, maoístas, situacionistas). La se- gunda, y quizá más importante, la incidencia de los hechos en el debate ideológico inmediato y en la activación del pensamiento post-68. Los nombres que suelen barajarse, con mayor o menor fundamento, se confunden (Bourdieu, Castoriadis, Debord, Althusser, Marcuse, Sartre, Lacan, Foucault, Deleuze, Derrida, etc.) y ello ha contribuido a que se haya podido hablar de manera genérica de un pensamiento $68^{5}$, que no ha hecho sino prolongar la polémica y la batalla de la interpretación al filo de las conmemoraciones. En cualquier caso, al igual que el movimiento evidenció una enorme diversidad, si no cabe establecer un pensamiento unificado de la protesta, ello no impide valorar el mayor o menor peso y proyección de unas ideas respecto a otras.

Algunas individualidades han recibido mayor atención. La obra Les Héritiers de Bourdieu y Passeron (1964), denunciando los obstáculos que dificultaban el acceso de determinados grupos sociales a la universidad (o a centros concretos) y su éxito académico, fue señalada por Aron como uno de los catalizadores de mayo, aunque recientemente Cruel ha criticado sus tesis -reelaboradas por Bourdieu (1984) en el Homo academicus- rebatiendo su influencia en el origen de la crisis y en la radicalización de los activistas, supuestamente amenazados en su promoción social y futuro profesional (Cruel, 2004, pp. 47-50, pp. 61-62 y pp. 159-161). Por otro lado, Althusser (para el retorno a Marx) y Lacan (para el retorno a Freud) continúan siendo evocados por antiguos activistas como los principales referentes intelectuales del laboratorio de reflexión que fue l'École normale supérieure (donde también emergía Derrida entonces), muy politizada en los 60, en la estela de las guerras de Argelia y Vietnam, pero carente del dinamismo del foco principal estudiantil de la Sorbona (Delacroix, 2015; Dubois, 2010, pp. 193-195). Los maos de la calle Ulm, pese a su inspiración althusseriana, se implicaron poco en las jornadas de mayo, a diferencia de los troskistas, visibles estos en las barricadas. Será después de los sucesos cuando los maoístas concedan importancia a la fusión de estudiantes y obreros, queriendo establecer el paralelismo con el mito de la gran revolución cultural proletaria china, y alcanzando protagonismo durante la contestación de los años posteriores (Le Goff, 1998, pp. 173-181).

Sartre, encarnando la figura del intelectual total, ha pasado como el verdadero puente intelectual del 68 que establece la conexión entre la atmósfera pesimista de la posguerra y los nuevos vientos optimistas de cambio. Alumno y maestro del gauchisme, quiso ser el 
filósofo del movimiento, siempre a la búsqueda de la buena revolución y del nuevo intelectual comprometido (Delannoi, 1989, p. 26 y pp. 31-32), aunque quizá quien mejor encarnó ese compromiso revolucionario con los jóvenes -alimentando la unidad de acción entre estudiantes, obreros y escritores- fuese Maurice Blanchot (Brillant, 2003, p. 188, pp. 267-268, p. 517 y pp. 555-556). Sartre no gozó del favor de los situacionistas $y$, después de entrevistar a Cohn-Bendit ${ }^{6}$ y de consignar su percepción de los hechos (Sartre, 1968), no ocultaría su proximidad con el maoísmo en los primeros años 70. Si Sartre fue pontífice, Marcuse ha sido referido como profeta del 68 -las tesis de su libro El hombre unidimensional (1964) habrían quedado confirmadas por la revuelta-, aunque últimamente se niegue con determinación su proyección en el escenario francés (Duteuil, 2008, p. 197; Loyer, 2008, p. 36; Ross, 2002/2008, pp. 367-368; Zancarini-Fournel, 2008, p. 192), desconociendo muchos datos al respecto: su misma presencia en París en el corazón de mayo o la referencia a su pensamiento en los muros de la ciudad. La obra de Marcuse adquirió una audiencia masiva después de los sucesos, pero se traduce y difunde en Francia durante las jornadas de mayo, y en la Sorbona ocupada por los estudiantes se leía mucho. Tampoco puede obviarse la cercanía del pensamiento de Marcuse, en aspectos esenciales, con los postulados situacionistas (Combes, 1984, pp. 87-90 y p. 110), aunque estos tuvieran en La sociedad del espectáculo de Debord (1967) y en el Tratado del saber vivir para uso de las jóvenes generaciones de Vaneigem (1967) sus referentes inmediatos (Chollet, 2015).

Fuera de planteamientos causalistas, el gran rechazo a la sociedad industrial avanzada que preconizaba Marcuse se hizo particularmente visible en el 68 francés, aunque el primer sorprendido por la coincidencia entre algunas de las ideas que sugirió y las formuladas por los jóvenes fuese él (Marcuse, 1969, pp. vii-x). Marcuse no había valorado en su libro de 1964 las potencialidades revolucionarias de la juventud y hubo de revisar a la luz del 68 francés la desconsideración efectuada de los trabajadores como sujeto revolucionario en el presente, cuestión central en el debate mantenido en el seno del marxismo durante los Treinta Gloriosos y que se superpone a la propia discusión sobre el 68. En vísperas del 68, Marcuse, preguntado en Berlín por la alternativa concreta a la sociedad existente, contestaba: "es por el momento la negación, pero en la negación misma se encuentra ya lo positivo". Certeau viene a coincidir con él cuando tras la experiencia de la toma de la palabra afirmaba: "lo que ha sido vivido positivamente no ha podido enunciarse más que negativamente". Marcuse no avanza en este punto después de mayo. Esta indefinición de la alternativa es lo que empuja a Aron a argumentar sobre la inexistencia de la revolución del 68 , pues no considera alternativa real los planteamientos de corte anarcosindicalista formulados entonces. $Y$ dialogando con Marcuse, insiste en que el rechazo de la sociedad de consumo no define un objetivo, sino que "expresa una revuelta emocional y moral que no puede traducirse en un programa político" (Aron, 1968, p. 118) ${ }^{7}$. Observación que recobra hoy validez, en determinados contextos, aunque pueda matizarse.

Touraine -el maestro de Cohn Bendit en Nanterre- se apresuró a anunciar un "nuevo período de la historia social" donde las nuevas luchas sociales no estarían protagonizadas por la "élite obrera", pero tampoco es capaz de precisar mucho más, todo estaba por descubrir: comenzaba ahora, "a la luz de mayo", un "largo trabajo teórico y práctico" (Touraine, 1968, p. 143 у pp. 288-289). El 68 hizo entender en la calle, y ayudó a replantear, cuestiones sobre las que trabajaban los intelectuales, como eran las mismas relaciones entre lenguaje, poder y política; los límites de los actuales modelos de organización económica; las nuevas exigencias de emancipación o la naturaleza de los nuevos movimientos sociales. Fue el 68 quien movilizó a los intelectuales, no al revés, llevando a la politización del propio discurso filosófico (Pinto, 1989, p. 45) y al compromiso de aquellos de permanecer junto a quienes luchan contra el poder y la represión, en lugar de caer en la "indignidad de pretender hablar por ellos" (Foucault-Deleuze) ${ }^{8}$. A la liberación de la palabra siguió la conceptualización de la liberación del deseo, como requerimiento de una voluntad libre. Distanciándose de Lacan, la obra de Deleuze -descubridor de Nietzsche en Francia- aliado con Guattari adquiere significación en ese sentido. El deseo no como carencia sino como producción y extensión del campo social, y aun como "instancia revolucionaria" contra el dominio del interés en la sociedad presente (Deleuze-Guattari, 1972, pp. 36-37, p. 42 y p. 458). La revolución se sostiene en el deseo, no en el deber. La contestación gauchiste post- 68 beberá también en estos autores y en Foucault (1975) para decretar la liberación del cuerpo, entronizado como "máquina deseante" una vez desembarazado

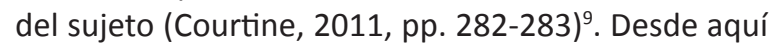
se explica mejor el alumbramiento del feminismo en Francia, inexistente como tal en el 68, según han valorado señaladas activistas (Formaglio y Lechevallier, 2010, p. 170 y pp. 174-176), y su repercusión en la implosión del gauchisme $e^{10}$. 
La radicalización del deseo como apología de la subversión general acabó evidenciando el carácter de la contracultura -en Francia y fuera de ella- como negación de una acción auténticamente innovadora. Marcuse criticó enseguida el "radicalismo inapropiado" de determinadas manifestaciones contraculturales e hizo ver que la revolución "no es nada sin su propia racionalidad" (Marcuse, 1972, p. 129 y p. 132), lo que suponía igualmente un reconocimiento de la crisis teórica del marxismo, agravada tras el movimiento de mayo. El neomarxismo revolucionario pretendido por Althusser -en clave de antihumanismo teóricohabía quedado desbordado por el propio imaginario del 68. Ya antes de esa fecha, Castoriadis había defendido el abandono de Marx en favor de la revolución, inspirando a sesentayochistas como Cohn-Bendit. Trasladando junto a Morin y Lefort su visión de los acontecimientos, Castoriadis se opuso a cualquier comparación de mayo con la revolución cultural china y exaltó la autogestión -la plena autonomía individual y social, y la exigencia de "la elección y la revocabilidad permanente" de cualquier responsabilidad (Morin, Lefort y Castroriadis, 1968, p. 108)-como reverso de la lucha contra todas las jerarquías y las burocracias, idea que conduciría a la propia fragmentación y descomposición de los grupos gauchistes (hasta disolverse en la cultura posmoderna). Independientemente de la audiencia conseguida durante el post-68, la voluntad de estos autores de llevar la crítica al marxismo y el totalitarismo "hasta el núcleo de la teoría marxista" (Lefort, 1971, postfacio) tuvo particular eco y traducción después de 1975, coincidiendo con la irrupción en el debate de los nuevos filósofos, quienes acabarán perfilando el nuevo tipo del intelectual mediático e introduciendo también un nuevo sesgo en la discusión sobre el 68, en las proximidades de la primera conmemoración.

\section{CONMEMORACIONES Y REINTERPRETACIONES DEL 68}

Hacia 1975 se produce un verdadero cambio de telón. En sus distintas vertientes, el gauchisme político y el mismo debate ideológico post-68 desarrollado dentro del cuadro marxista-libertario, se diluyeron con relativa facilidad. La llamada nueva filosofía, articulada en 1975-1976 alrededor de nombres como Levy, Glucksmann, Jambet o Lardreau, alcanzó enseguida gran difusión editorial y mediática, y condicionaría la conmemoración de 1978, al tratarse de antiguos gauchistes (maoístas en su mayoría) que de alguna manera se declaraban los herederos del movimiento, estableciendo y rompiendo relaciones con el pensamiento de los 60 y primeros $70^{11}$. Con ellos la crítica sesentayochista del poder adquiere un aire tremebundo, presentado el estado como la nueva encarnación del mal, al tiempo que establecen un vínculo directo entre marxismo y Goulag, utilizando a Solzhenitsyn, para recuperar el discurso de los derechos humanos frente a la "extrema izquierda reaccionaria" o el "fascismo marxista" (Glucksmann, 1975; Glucksmann, 1977; Levy, 1977) ${ }^{12}$. La lucha antiautoritaria se transforma en lucha antitotalitaria. Para Ross (2002/2008, p. 41), y detrás otros autores, los nuevos filósofos habrían borrado las huellas de mayo, siendo por ello los principales responsables de la distorsión de su ideología y legado. La primera manifestación del giro interpretativo es la "modesta contribución" de Regis Debray (1978) al décimo aniversario. Según este antiguo guerrillero encarcelado durante mayo y más tarde colaborador de Mitterand, el 68 provocó un cortocircuito entre las dos Francias, la nueva y la vieja: la Francia dinámica y expansiva desde el plano económico, y la anquilosada atendiendo al marco socio-institucional y a las mentalidades. Un cortocircuito que obliga a revisar la instalación, no a cambiar el sistema. Convencido de la indestructibilidad del mismo, considera que los sucesos del 68 abrieron una nueva vía al desarrollo del capitalismo y la democracia, de ahí que mayo pueda entenderse como la revolución cultural del capitalismo, apunta Cassen (1978, septiembre) a raíz del libro. Y aludiendo indirectamente al paralelismo establecido por Certeau entre la toma de la Bastilla y la toma de la palabra, concluye Debray: "Mayo del 68 es la cuna de la nueva sociedad burguesa". Lo importante, considera, es lo que la historia ha hecho del movimiento, y no lo que este ha creído hacer ${ }^{13}$. Muchos militantes pudieron sentirse huérfanos (Guillebaud, 1978).

La polémica abierta por Debray llega hasta el 20.ㅇ aniversario. En su análisis había valorado igualmente el significado del 68 como emancipación del individuo dispuesto a "liquidar las dos religiones solidarias y concurrentes de la nación y el proletariado" (Debray, 1978, p. 41). Lipovetsky, perteneciente a la segunda generación de los nuevos filósofos, desarrolla ampliamente la cuestión haciendo del 68 el catalizador del individualismo narcisista triunfante en los años 80 . Aunque parte de la noción de Tocqueville -el repliegue egoísta del individuo sobre la esfera privada- para definir el fenómeno, Lipovetsky no discute el carácter movilizador y participativo del 68. Esa es una dimensión del hecho, pero históricamente la más significativa fue otra, lo que tuvo de explosión individualista. La misma reacción antijerárquica y la liberación de la palabra que traduce el movimiento, son signos de un 
individualismo transpolítico inseparable de la reivindicación de la independencia personal. El 68 provoca así una reevaluación de lo privado, lo que supone un salto adelante en la lógica individualista: el derecho a la libertad, en teoría ilimitado pero hasta ahora socialmente circunscrito a la economía, la política o el saber, se extiende a las costumbres y alcanza el ámbito de lo cotidiano (Lipovetsky, 1983). Al margen del recorrido del debate, no puede obviarse la raíz individualista propia del pensamiento libertario que incorporó la llamada a la revolución de la vida cotidiana realizada por los situacionistas, junto a su apoyo a la causa obrera y la autogestión (Ghirardi, 2003, p. 3, pp. 46-47, p. 99 у p. 105). Tampoco debe ignorarse que fue Marcuse posiblemente el primero en percibir la esencia del 68 en clave de advenimiento de un nuevo individualismo (Sánchez-Prieto, 2014, pp. 89 y ss.) ${ }^{14}$.

Luc Ferry vino a prolongar los desarrollos de Debray y Lipotvetsky, concitando la mayor parte de las críticas posteriores por su pretendida invención de un pensamiento 68 alejado de los hechos y los actores (Ferry y Renaut, 1985), aunque no se ha retenido tanto el diálogo que mantuvo con Castoriadis -fiel este a sus principios-, forzando la interpretación del 68 en clave liberal ${ }^{15}$. Para Ferry, el 68 se sitúa a medio camino entre las grandes revoluciones del siglo XIX y el nuevo individualismo de los 80 , y como aquellas -por eso su reiteración- no llega ni a romper el sistema que rechaza ni a inscribirse verdaderamente en formas institucionales nuevas ${ }^{16}$. Siendo el 68 un movimiento esencialmente antijerárquico y antitradicional-lo cual comparte Castoriadis entendido desde la socialización-, aquel no se encarnó políticamente sino socialmente, sostiene Ferry. El 68 no fue un movimiento político, que habría fracasado -de atender al ideal de la autogestión, que Castoriadis continúa invocando-, sino un movimiento social que triunfó, más allá de lo previsible, en la liberación de las costumbres que produjo, concluye Ferry (Castoriadis, 1986, pp. 107-109 у pp. 114-116; Ferry y Renaut, 1987, pp. 31-35, pp. 57-61 у pp. 70-71).

La primera crítica a Lipovetsky y Ferry durante el vigésimo aniversario provino de un antiguo trotskista (socialista a partir de los 80), Henri Weber, pero fue bastante contenida, pues se acababa asumiendo la interpretación individualista, aunque matizada. Frente al individualismo egoísta tocquevilleano del primero y el individualismo revolucionario del segundo, Weber (1988/1998) contempla un individualismo propiamente democrático compatible con las ideas comunitarias y solidarias. La crítica más dura la formulará tardíamente Ross, como si quisiera entrar a destiempo en el debate, reaccionando contra lo que considera la despolitización de mayo, reducido en los 80 a una pura cuestión cultural o de costumbres, aunque curiosamente sus referencias a Ferry se ciñen únicamente a las tesis del autor sobre el pensamiento del $68^{17}$. En su cruzada contra el legado interpretativo del 20. aniversario, Ross incluye igualmente la obra de Hamon y Rotman (1987-1988), a la que responsabiliza de haber fabricado una imagen elitista del 68, a partir de un grupo pequeño de supuestos héroes, que deja de lado la experiencia de miles de personas, para afianzar la idea romántica de una revolución puramente cultural alejada de las masas y de la política colectiva. Para la autora, la nueva ola de movilizaciones iniciada en Francia a mediados de los 90, certificaría la desviación de la interpretación culturalista (Ross, 2002/2008, pp. 377-388 y pp. 393-398), aunque la verdad es que ese rebrote obrero no tuvo incidencia en la conmemoración del 30. aniversario. Sin negarle valor académico, el trabajo de Ross no oculta -como han puesto de manifiesto otros historiadores (Gildea et al., 2013, p. 284)- una intención política de reformular el proyecto del 68 para hacerlo efectivo en el presente. O lo que es lo mismo, una voluntad de revivir el mito.

Contrariamente a lo indicado por Reynolds (2011, p. 45), para quien desde el vigésimo aniversario no se habría prestado ninguna atención a este debate inconcluso de las interpretaciones del 68, lo cierto es que este no se detuvo y acabó consagrando el giro cultural, en la percepción y valoración del 68, durante el 30. aniversario, fuera del cuadro del individualismo humanista de derecha y del propio ámbito francés. Las obras de Le Goff y Marwick -ignoradas por Ross- son importantes en este contexto. La primera supone una mirada crítica desde la izquierda y para la izquierda, centrada en los efectos disolventes de la contracultura gauchiste, que hace del 68 una "herencia imposible". Le Goff se opone así a cualquier lectura positiva del acontecimiento en términos de modernidad (o posmodernidad) cultural. El 68, arrastrado por el mito revolucionario y la pasión de vivir, hizo de la autonomía individual un absoluto que se vuelve contra cualquier estructuración y mediación social, así como contra cualquier sentimiento de obligación o deber con respecto a las generaciones pasadas y futuras. Los ochenta, en su componenda liberal-libertaria de trasfondo económico, no han definido la verdad del 68. Es preciso superar el "síndrome del tabula rasa" y la instalación en el nuevo conformismo para reconstruir los fundamentos culturales y éticos de la convivencia, explorando nuevas vías de compromiso de la ciudada- 
nía con la política y el Estado, concluye (Le Goff, 1998, pp. $16-19$, pp. $350-351$ y pp. $457-464)^{18}$. Por su parte, la obra de Marwick (1998), sin limitarse al caso francés y situada al margen de la polémica francesa, tuvo el poder de disolver los aspectos más criticados de la contracultura en una amplia y generosa comprensión de los años 60 como revolución cultural, haciendo valer a la postre la interpretación culturalista del 68.

Dentro de una gran floración de títulos y reediciones ${ }^{19}$, el 40.0 aniversario evidenció el juego de interpretaciones y memorias enfrentadas, antes que la cristalización de cualquier consenso. La irrupción de Sarkozy, durante la campaña presidencial de 2007, prometiendo "liquidar definitivamente" el 68, incorporaba la mirada del acontecimiento desde el poder, emulando a de Gaulle, con miras a rentabilizar políticamente la interpretación más crítica del 68. La imagen a su lado de Glucksmann -símbolo de los nuevos filósofos treinta años antes- reforzaba el efecto. $Y$ Cohn-Bendit (2008) no desaprovechó la celebración para rubricar en términos personales su prolongado Forget 68. Había que enterrar la memoria del 68. Audier, en su afán de esclarecer la trama intelectual de dicha involución, incide en el mito del ilocalizable pensamiento 68 para construir la genealogía de 'un' pensamiento anti-68 que queda expuesto a la misma crítica comúnmente realizada a Ferry, aunque intente soslayarla hablando de pluralidad en su seno (Audier, 2008, p. 12). El otro frente del debate lo establecen quienes no se resignan a una simple rehabilitación cultural del 68 -la aceptación de la revolución de las costumbres y las mentalidades-, y espoleados por la obra de Ross y las nuevas movilizaciones sociales de mediados de los años 90 y primeros 2000, luchan contra el olvido y reivindican su proyección política actual. Las obras de Cusset y Duteuil, antiguos militantes particularmente críticos con la traición de la izquierda a la memoria del 68 (Cusset, 2008, p. 30, p. 45 , p. 55 , pp. $90-91$ у p. 97 ), son significativas en ese sentido y continúan alimentando el ideal de ruptura frente al reformismo acomodaticio.

Estas críticas de los fieles contra los renegados en el seno del viejo gauchisme han llevado a los propios historiadores a recuperar otras muchas voces anónimas, a los olvidados, y a reconstruir el perfil del activista. Voces que revelan una experiencia subjetiva del descubrimiento de la propia conciencia política; de implicación en una acción colectiva radical que se recuerda como un momento clave en la construcción de la propia identidad personal. Voces que evocan el sentimiento de injusticia social en el marco de la pros- peridad económica y la descolonización, por encima del anticapitalismo y antiimperialismo militantes. Voces que reviven la falla entre democracia y rigidez institucional; el aprendizaje familiar del antifascismo o el rechazo del acomodamiento de los padres; la actitud personal frente a la resignación religiosa o el ateísmo militante; la búsqueda de modos alternativos de vida; la experiencia de la sexualidad y su repercusión de prolongado alcance en el sentido del yo. Todo ello se mezcla de manera reflexiva en la fabricación de las distintas memorias individuales, componiendo historias de vida que no responden a un único patrón y que traducen la misma tensión y pluralidad de los debates públicos, al quedar expuestas igualmente a un tiempo político cambiante y transformador que obliga a rehacer el propio relato, integrando esa y otras experiencias vividas al margen del activismo en un todo más o menos coherente donde se resuelve finalmente la comprensión de uno mismo (Gildea et al., 2013, p. 44, p. 71, p. 103 , p. 257 y pp. 324-325). Es la misma dificultad que encuentran los historiadores para escribir la historia en tiempos de memoria ${ }^{20}$, sometidos ellos mismos al poder del mito y de la crítica.

\section{A MODO DE CONCLUSIÓN: LA AMBIVALENCIA DEL LEGADO}

¿Qué queda del 68? La pregunta se repite desde el día siguiente y presidirá seguramente la conmemoración del cincuentenario. Para Weber, que la planteó en 1988 y retomó en 1998, los efectos del 68 en la actualidad son de orden simbólico y mitológico, si se prescinde del apego a los valores hedonistas y democráticos (Weber, 1988/1998, pp. 18-19). El mito perdura y se fortalece de conmemoración en conmemoración, pero cuál es la verdad del mito del 68 y qué es lo que le hace vulnerable a la crítica, esas son las preguntas difíciles de contestar. Su romanticismo y mesianismo apelan a la búsqueda de sentido, a la posibilidad liberadora de forjar un mundo radicalmente distinto que mire a las personas y no a las cosas. "Lo posible, creado por el acontecimiento, quedó en suspenso" apunta Canut (2011, p. 25), dada la inconcreción política del movimiento y la ausencia de un lenguaje común, de ahí que las nuevas subjetividades surgidas con él no dejen de llamar a la puerta intentando llenar ese gran vacío creado por la mitificación. El 68 ciertamente no pertenece a nadie y por ello ha acabado erigiéndose en precursor de todo para gozar de perenne actualidad.

De cualquier forma, hay aspectos que pueden retenerse. La movilización fue expresión de una poli- 
tización masiva, que cuanto menos manifiesta una voluntad de presencia y participación ciudadana, de vivificar las instituciones tanto como el lenguaje, por más que la palabra liberada pueda perderse o vuelva a ser retomada por el sistema, como ya advirtió Certeau (1968, p. 64). La palabra viva del 68, desactivada por el lenguaje gerencial triunfante en los 80 , establece un doble compromiso con la creatividad y la crítica, entendidas como herramientas fundamentales para la construcción social, que mantienen su valor. No es un simple desahogo inconformista, ni una pura apelación a la libertad de expresión, que si por otra parte prescinde de la palabra de autoridad -y a ello también contribuyó el 68 con su rechazo de las jerarquías-, se convierte en vieja demagogia, como se comprueba hoy en el discurso de algunos grupos o movimientos que, en su origen, como el 68 , hicieron de la calle un lugar de la palabra al que atender y escuchar.

Con independencia de la existencia o no de un pensamiento 68 ligado al movimiento, no pueden ignorarse los efectos ideológicos del 68. Le Goff (2013) ha insistido en la influencia e impregnación actual del gauchisme cultural heredero de aquella revolución y en las fracturas que provoca en la sociedad (matrimonio homosexual, nuevo antifascismo, ecologismo mesiánico, educación de los hijos, posiciones identitarias, etc.). La sublimación subversiva del deseo hizo aflorar una cultura de la autenticidad donde el ser uno mis- mo en su propia singularidad se convierte en el valor supremo. Frente a la norma exterior, sea cual sea, se reivindica el derecho a afirmar la diferencia, sea cual sea. Las normas de vocación universal se eclipsan en beneficio de los particularismos, lo que dificulta seriamente la comunicación y el fortalecimiento del pensamiento: el pensamiento débil acaba identificado con el pensamiento correcto, soslayándose cualquier discusión sobre una política de límites ${ }^{21}$.

Esta es sin duda la parte más incómoda del legado del 68, y la que invita a reflexionar. De la dinámica de transgresión del orden establecido se ha pasado a la banalización actual de cualquier realidad, reducido todo a una única dimensión, que nos devuelve a la crítica marcuseana. El relativismo del 68 ha favorecido, por paradójico que pueda resultar respecto a la atmósfera en que se desenvolvió el movimiento, un nuevo conformismo -la instalación en el presente sin mayores expectativas de futuro- cuyos contornos ideológicos trascienden el individualismo liberal-libertario de los 80, tal y como sugiere Castoriadis (1997, pp. 32-47), al caracterizar el posmodernismo como conformismo generalizado. Esta ausencia de verdades madres facilita la disgregación de la comunidad, el abandono de la búsqueda de la unidad, y reduce la pluralidad a una amalgama (posmoderna) de espíritus que erosiona el sentido y el valor de la democracia. La actual amenaza o tentación populista, de derecha o izquierda, no es una casualidad.

\section{NOTAS}

1. Véase el análisis que desde esa perspectiva hace la autora de no pocos de los eslóganes de mayo.

2. Una selección de textos de esos comités puede verse en Loyer (2008, pp. 292-303)

3. Recogidos en Lewino (1968).

4. Desde esta perspectiva, los muros no reflejan en modo alguno el antihumanismo que Ferry y Renaut (1985) atribuyen al supuesto pensamiento del 68.

5. Ferry y Renaut lo circunscriben a los nombres de Bourdieu, Lacan, Foucault y Derrida.

6. Daniel Cohn-Bendit s'entretient avec Jean-Paul Sartre. Le Nouvel Observateur, 20 de mayo de 1968.

7. Sobre Marcuse y el 68 , y el diálogo de Aron, véase Sánchez-Prieto (2014).
8. 'Les intellectuels et le pouvoir', entretien de Michel Foucault avec Gilles Deleuze. L'Arc, 4 de marzo de 1972, pp. 3-10.

9. Este modo de entender la liberación del deseo y del cuerpo difiere de los planteamientos de los situacionistas sobre el deseo y la revolución, o de Marcuse sobre el eros.

10. Le Goff (1998, pp. 297 y ss.) relaciona la irrupción del feminismo -en torno a la creación y desarrollo del movimiento de liberación feminista (MLF) a partir de 1970- con la desarticulación del gauchisme.

11. Deleuze les juzgó como un simple producto de marketing cultural (Le Monde, 19 de junio de 1977). Véase también la crítica de Aubral y Delcourt (1977).

12. Un resumen de sus tesis en Le Goff (1998, pp. 409-419).
13. Viene a reafirmar a Certeau, para quien un acontecimiento "no es lo que se puede ver o saber de él, sino lo que se convierte para nosotros" (Certeau, 1968, p. 44).

14. Para Marcuse (1972, pp. 48, 131), "no cabe ningún cambio social radical sin un cambio radical de los agentes individuales de cambio". En su concepción, la liberación individual debía trascender los límites del individuo burgués (determinado por la tensión entre la realización personal y el funcionamiento social), pero restaurando al mismo tiempo la dimensión íntima del yo creada en su momento por la "cultura burguesa".

15. El análisis de Premat (2009) sobre las interpretaciones de mayo no sobrepasa los límites trazados por Ferry y Renaut en La pensée 68, sin explorar los efectos de la crítica al libro en la 
prolongación del diálogo mantenido por estos autores con Castoriadis.

16. En este sentido, no difiere de la visión historiográfica inmediata manifestada por Capdevielle y Mouriaux (1988) que entienden el 68 como un acontecimiento intermediario.

17. Véase Ross (2002/2008, pp. 361-365), siguiendo en esto a Castoriadis (1986, pp. 110-114).

\section{BIBLIOGRAFÍA}

Aron, R. (1968). La révolution introuvable. París: Fayard.

Artières, Ph. y Zancarini-Fournel, M. (dirs.) (2015). 68, une histoire collective (19621981). París: La Découverte.

Aubral, F. y Delcourt, X. (1977). Contre la nouvelle philosophie. París: Gallimard.

Audier, S. (2008). La pensée anti-68: essai sur une restauration intellectuelle. $\mathrm{Pa}$ rís: La Découverte.

Barthes, R. (1968). L'écriture de l'événement. Communications, 12, pp. 108-112. https:// doi.org/10.3406/comm.1968.1175

Bénéton, Ph. y Touchard, J. (1970). Les interprétations de la crise de mai-juin 1968. Revue française de science politique, 20 (3), pp. 503-544. https://doi. org/10.3406/rfsp.1970.393237

Bourdieu, P. (1984). Homo academicus. París: Minuit.

Bourdieu, P. y Passeron, J-C. (1964). Les Héritiers. Les étudiants et la culture. París: Minuit.

Brillant, B. (2003). Les clercs de 68. París: Presses Universitaires de France. https:// doi.org/10.3917/puf.brill.2003.01

Callu, A. (dir.) (2010). Le Mai 68 des historiens. Entre identités narratives et histoire orale. Villeneuve d'Ascq: Presses Universitaires du Septentrion.

Canut, C. (2011). Demain ce fut Mai. Politique sur paroles. En: Canut, C. y Prieur, J.-M. (dirs.) (2011). 1968-2008. Evénements de paroles. París: Michel Houdiard, pp. 11-29.

Capdevielle, J. y Mouriaux, R. (1988). Mai 68, l'entre-deux de la modernité. Histoire de trente ans. París: Presses de la Fondation National des Sciences Politiques.
18. Para Audier (2008, p. 352), al filo del 40. aniversario, Le Goff se mostró excesivamente crítico. Duteuil (2008, p. 13), viejo activista como Le Goff, lo desconsidera como simple "sociólogo de moda".

19. Una relación de las obras publicadas en Francia durante 2008 referidas al 68 puede verse en Sáenz de Miera (2009, pp. 210-244)

Cassen, B. (1978, septiembre). Mai 68 comme révolution culturelle du capitalisme. Le Monde diplomatique, p. 4.

Castoriadis, C. (1986). Les mouvements des années soixante. Pouvoirs, 39, pp. 107-116.

Castoriadis, C. (1997). World in Fragments. Stanford: Stanford University Press.

Certeau, M. (1968). La prise de parole. Pour une nouvelle culture. París: Desclée de Brouwer.

Chollet, L. (2015). Guy Debord et les situationnistes. En: Artières, Ph. y ZancariniFournel, M. (dirs.) (2015). 68, une histoire collective (1962-1981). París: La Découverte, pp. 180-188.

Cohn-Bendit, D. (1968). Le gauchisme. Remède à la maladie sénile du communisme. París: Seuil.

Cohn-Bendit, D. (2008). Forget 68. La Tour d'Aigues: I'Aube.

Combes, P. (1984). La Littérature et le mouvement de Mai 68. París: Seghers.

Cornils, I. y Waters, S. (eds.) (2010). Memories of 1968: International Perspectives. Berna: Peter Lang. https://doi. org/10.3726/978-3-0353-0030-7

Courtine, J.-J. (2011). L'invention du corps En: Canut, C. y Prieur, J.-M. (dirs.) (2011). 1968-2008. Evénements de paroles. París: Michel Houdiard, pp. 277-284.

Cruel, L. (2004). La Rebellion de 1968. Une relecture sociologique. Rennes: Presses Universitaires de Rennes.

Cusset, F. (2008). Contre-discours de mai. Ce qu'embaumeurs et fossoyeurs de 68 ne disent pas à ses héritiers. Arles: Actes du Sud.

Daum, N. (ed.) (1988). Des révolutionnaires dans un village parisien. París: Londreys.
20. La expresión es de Juliá (2011).

21. La expresión es de Gitlin (2006, pp. 84-86), que entiende esa política como potencialmente radical y conservadora a la vez.

Debord, G. (1967). La société du spectacle. París: Buchet-Chastel.

Debray, R. (1978). Modeste contribution aux cérémonies officielles du dixième anniversaire. París: Maspero.

Delacroix, Ch. (2015). L'engagement radical de la rue d'Ulm. En: Artières, Ph. y Zancarini-Fournel, M. (dirs.) (2015). 68, une histoire collective (1962-1981). París: La Découverte, pp. 125-131.

Delannoi, G. (1989). Mai et les sciences sociales dans l'évolution idéologique de l'après-guerre. En: Bedarida, F. y Pollak, M. (dirs.) (1989). Mai 68 et les sciences sociales. París: Institut d'Histoire du Temps Présent, 11, pp. 27-37.

Deleuze, G. y Guattari, F. (1972). L'AntiOedipe. Capitalisme et schizophrénie. París: Minuit.

Dosse, F. (2010). Le cas de l'événement Mai 68 : une prolifération de sens. En: Renaissance de l'événement. París: Presses Universitaires de France, pp. 261-272.

Dubois, A. (2010). L'École nationale des Chartes versus l'École normale supérieure: dissemblances. En: Callu, A. (dir.) (2010). Le Mai 68 des historiens. Entre identités narratives et histoire orale. Villeneuve d'Ascq: Presses Universitaires du Septentrion, pp. 185-196.

Dubois, M. (2014). Génération politique: les 'années 68' dans les jeunesses des partis politiques en France et en RFA. Paris: Presses Universitaires de Paris-Sorbonne.

Duteuil, J.-P. (2008). Mai 68. Un mouvement politique. La Bussière: Acratie.

Ferry, L. y Renaut, A. (1985). La pensée 68. Essai sur l'anti-humanisme contemporain. París: Gallimard.

Ferry, L. y Renaut, A. (1987). 68-86. Itinéraires de l'individu. París: Gallimard. 
Formaglio, C. y Lechevallier, A.-S. (2010). Femmes, quels partis pris? Féminisme et gender studies. En: Callu, A. (dir.) (2010). Le Mai 68 des historiens. Entre identités narratives et histoire orale. Villeneuve d'Ascq: Presses Universitaires du Septentrion, pp. 169-182.

Foucault, M. (1975). Surveiller et punir. París: Gallimard.

Gassert, Ph. y Klimke, M. (eds.) (2009). Memories and Legacies of a Global Revolt. Washington: German Historical Institute.

Geismar, A., July, S. y Morane, E. (1969). Vers la guerre civile. París: Editions et publications premières.

Ghirardi, S. (2003). Nous n'avons pas peur des ruines. Les situationnistes et notre temps. París : L'insomniaque.

Gildea, R., Mark, J. y Warring, A. (eds.) (2013). Europe's 1968: voices of revolt. Oxford: Oxford University Press. https://doi.org/10.1093/acprof:o so/9780199587513.001.0001

Gitlin, T. (2006). The intellectuals and the flag, Nueva York: Columbia University Press.

Glucksmann, A. (1975). La cuisinière et le mangeur d'hommes. Essai sur l'Etat, le marxisme, les camps de concentration. París: Seuil.

Glucksmann, A. (1977). Les maîtres penseurs. París: Grasset.

Guillebaud, J-C. (1978). Les années orphelines, 1968-1978. París: Seuil.

Hamon, H. y Rotman, P. (1987-1988). Génération. París: Seuil.

Juliá, S. (2011). Elogio de Historia en tiempo de Memoria. Madrid: Marcial Pons.

Le Goff, J.-P. (1998). Mai 68, l’héritage impossible, París: La Découverte.

Le Goff, J-P. (2008, 30 mayo). Un événement qui n’appartient à personne. Le Figaro.
Le Goff, J.-P. (2013). Du gauchisme culturel et de ses avatars. Le Débat, 176 pp. 39-55. https://doi.org/10.3917/ deba.176.0039

Lefort, C. (1971). Eléments d'une critique de la bureaucratie. Ginebra: Droz. https:// doi.org/10.3917/droz.lefor.1971.01

Levy, B.-H. (1977). La barbarie à visage humain. París: Grasset.

Lewino, W. (1968). L'imagination au pouvoir. París: Le Terrain Vague.

Lipovetsky, G. (1983). L'Ère du vide. Essai sur l'individualisme démocratique. París: Gallimard.

Loyer, E. (2008). Mai dans le texte. París: Éditions Complexe.

Marcuse, H. (1964). One-dimensional man. Studies in the ideology of advanced industrial society. Boston: Beacon Press.

Marcuse, H. (1969). An Essay on Liberation. Boston: Beacon Press.

Marcuse, H. (1972). Counterrevolution and revolt. Boston: Beacon Press.

Marwick, A. (1998). The Sixties. Cultural Revolution in Britain, France, Italy, and the United States, 1958-1974. Oxford: Oxford University Press.

Morin, E., Lefort, C. y Castoriadis, C. (1968). Mai 68: la bréche. Premières réflexions sur les événements. París: Fayard.

Nora, P. (1972). L'événement monstre. Communications, 18, pp. 162-172. https:// doi.org/10.3406/comm.1972.1272

Nora, P. (2011). Présent, nation, mémoire. París: Seuil.

Perrot, M. (1993). Mémoires de 68. Guides des sources d'une histoire à faire. París: Verdier.

Pinto, L. (1989). Mai 68 et le rapport des philosophes aux sciences de I'homme. En: Bedarida, F. y Pollak, M. (dirs.) (1989). Mai 68 et les sciences sociales. París: Institut d'Histoire du Temps Présent, 11, pp. 39-59.
Premat, Ch. (2009). Mai 68, le conflit des interprétations. Sens public, 2, pp. 3-10.

Reynolds, C. (2011). Memories of May 68: France's Convenient Consensus. Cardiff: University of Wales Press.

Rohan, M. (1988). Paris 68: graffiti, posters, newspapers and poems of the events of May 1968. Londres: Impact Books.

Ross, K. (2002/2008). Mayo del 68 y sus vidas posteriores. Madrid: Acuarela.

Saénz de Miera, A. (2009). 40 años del 68 francés. Norba, 22, pp. 205-244.

Sánchez-Prieto, J. M. (2001). La historia imposible del Mayo francés. Revista de Estudios Políticos, 112, pp. 109-133.

Sánchez-Prieto, J. M. (2014). Herbert Marcuse y el espíritu neorromántico de la protesta. En: Sánchez-Capdequí, C. (ed.) El dinamismo de los valores. Barcelona: Anthropos, pp. 53-94.

Sartre, J.-P. (1968). Les communistes ont peur de la révolution. París: Didier.

Touraine, A. (1968). Le mouvement de mai ou le communisme utopique. París: Seuil.

Vaneigem, R. (1967). Traité de savoir-vivre à l'usage des jeunes générations. París: Gallimard.

Vivero, M. D. (2011). Sous les paroles... des paroles. Humour, parodie et contestation dans les slogans de mai 68. En: Canut, C. y Prieur, J.-M. (dirs.) (2011). 1968-2008. Evénements de paroles. París: Michel Houdiard, pp. 323-334.

Weber, H. (1988/1998). Que reste-t-il de mai 68. Essai sur les interprétations des 'Événements'. París: Seuil.

Zancarini-Fournel, M. (2008). Le moment 68. Une histoire contestée. París: Seuil. https://doi.org/10.14375/ NP.9782020898911 